\title{
Produção de mudas de cultivares de alface utilizando duas espumas fenólicas em Altamira, Pará
}

\section{Seedling production of lettuce cultivars using two phenolic foams in Altamira, Pará}

\author{
Alzirio L. Couto $^{1}$ *, Djair A. Moreira ${ }^{2}$, Pedro Vitoriano de Araujo Junior ${ }^{3}$
}

Resumo: O sucesso de qualquer produção comercial de hortaliças inicia-se com a produção de mudas. A espuma fenólica tem se mostrado um interessante e prático substrato para este processo. A utilização deste produto depende de uma lavagem precedente para reduzir a acidez. Porém, já é possível encontrar à venda espumas fenólicas com pH próximo. Por isso o objetivo deste trabalho foi avaliar a produção de mudas de cultivares de alface utilizando duas espumas fenólicas em Altamira, Pará. O delineamento constou de um esquema fatorial 2 (substratos) x 6 (cultivares). Os dois substratos foram as espumas fenólicas Green Up®, com pH 6.0 ( \pm 0.5)., e a outra com pH 2.6 ( \pm 0.5$)$. As cultivares avaliadas foram: Alcione, Amanda, Lucy Brown, Caipira, Multiblond 3 e Solaris. Foi avaliada porcentagem de germinação, índice de velocidade de emergência, altura da planta e número de folhas. Houve diferença significativa para altura da planta em função dos substratos testados. A porcentagem de germinação mais elevada foi obtida com a espuma fenólica sem tratamento. A cultivar Caipira foi a que teve o menor desempenho na germinação. Para todas as variáveis analisadas, a cultivar Lucy Brown apresentou os melhores resultados em ambos os substratos.

Palavras-chaves: Lactuca sativa L., hidroponia, substrato, produção de mudas.

\begin{abstract}
The success of any commercial vegetable production begins with the production of seedlings. Phenolic foam has been an interesting and convenient substrate for this process. The use of this material depends on a previous washing to reduce acidity. However, it is possible to find sale phenolic foams with near neutral $\mathrm{pH}$. So it the aim of this study was to evaluate the production of seedlings of lettuce cultivars using two phenolic foams in Altamira, Pará. The design consisted of a factorial 2 (substrates) x 6 (cultivars). The two substrates were Green Up® phenolic foams, $\mathrm{pH} 6.0( \pm 0.5)$. And the other at $\mathrm{pH} 2.6( \pm$ 0.5). The cultivars were: Alcyone, Amanda, Lucy Brown, Caipira, Multiblond 3 and Solaris. Germination percentage, speed of emergence index, plant height and number of leaves was assessed. Was no significant difference for plant height in relation to substrates tested. The higher percentage of germination was obtained with phenolic foam without treatment. The cultivar was a Caipira who had the lowest performance during germination. For all variables analyzed, the cultivar Lucy Brown presented the best results in both substrates.
\end{abstract}

Keywords: Lactuca sativa L., hydroponics, substrate, seedling production.

\footnotetext{
*Autor para correspondência

Recebido para publicação em 16/12/2014; aprovado em 25/01/2015

${ }^{1}$ Graduando em Agronomia pela Universidade Federal do Pará (UFPA). Acesso cinco, 1722. Sudam II. 68374-440. Altamira-PA. E-mail: alziriolino@gmail.com.

${ }^{2}$ Eng. Agr. Dr. Professor da Universidade Federal do Pará (UFPA). Cel. José Porfírio, 2515. São Sebastião. Campos II. 68372-040. Altamira-PA. E-mail: djair@ufpa.br.

${ }^{3}$ Especialista em recursos agroflorestais da Amazônia pela Universidade Federal do Pará (UFPA). Travessa Comandante Castilho, 221. Centro. Altamira-PA.

E-mail: pedrojunior8@yahoo.com.br.
} 


\section{INTRODUÇÃO}

A alface é uma planta anual, de clima ameno, que pertence à família Asteracea, é uma das hortaliças mais populares e consumidas em todo o Brasil e no mundo (HENZ; SUINAGA, 2009).

Paralelo a esta situação encontra-se a perspectiva de uma agricultura sustentável, que exige mudanças nas práticas agrícolas para conservar os recursos naturais e produzir alimentos saudáveis, e que permita ao produtor acesso a tecnologia de produção e maior perspectiva de renda agrícola.

O uso da técnica hidropônica como alternativa de produção pode ser inserida em um contexto sustentável, uma vez que se configura entre as práticas agrícolas de sucesso na olericultura, com vantagens nos aspectos econômico, ambiental e produtivo (CAVARIANNI et al., 2004).

Além disso, como uma forma de minimizar o uso e ocupação do solo, diversos autores (TRAVASSOS et al., 2011; SANTOS JUNIOR et al., 2011; MACIEL et al., 2012) vêm pensando em uma maneira de utilizá-la de uma maneira indireta, e para isso apontam as técnicas de hidroponia como uma boa alternativa para sanar esta problemática em alguns casos.

Dessa forma, esta técnica se apresenta como alternativa vantajosa e vem se expandindo rapidamente nas proximidades dos grandes centros urbanos, onde as terras agricultáveis são escassas e caras, havendo grande demanda por produtos hortícolas (LUZ et al., 2006).

Contudo, o sucesso de qualquer produção comercial de hortaliças inicia-se com a produção de mudas. E para a obtenção de mudas de boa qualidade se faz necessário observar alguns cuidados, como as características do substrato, necessidades hídricas e a nutrição mineral das plântulas.

Mudas vigorosas contribuem para dar resistência contra os danos mecânicos no momento do transplante, boa capacidade de adaptação ao novo ambiente e, portanto, redução no ciclo de produção, além de maior resistência a doenças (TRANI et al., 2004).

Um substrato ideal, de acordo com Kämpf (2001), deve ter de 75 a $90 \%$ de seu volume total ocupado por poros que serão preenchidos por ar ou água, ou ainda valores maiores que $90 \%$ no caso de cultivos em bandejas com poucos centímetros de altura, para que possa haver uma troca gasosa eficiente.

De acordo com Setubal e Neto (2000), o substrato deve apresentar características físicas, químicas e biológicas apropriadas para que possa permitir pleno crescimento das raízes e da parte aérea.

Os substratos utilizados no sistema hidropônico, mais do que exercer a função de suporte às plantas, proporcionam adequado suprimento de ar e água ao sistema radicular. Esses devem ser isentos de fitopatógenos, de fácil manejo, baixo custo e alta disponibilidade. Quatro principais tipos de substratos para produção de mudas para hortaliças folhosas têm sido usadas no cultivo hidropônico, a saber: substrato organo-mineral, vermiculita, algodão hidrófilo e espuma fenólica (FURLANI et al., 2009).

Alguns autores também têm estudado a utilização de substratos alternativos a partir de materiais predominantes em suas regiões como a palha de arroz (MEDEIROS; STRASSBURGER; ANTUNES, 2008), bagaço de cana de açúcar (PAULA et al., 2011), casca de amendoim (MELO et al., 2012), fibra de coco (QUEIROZ et al., 2013) e areia lavada.

A espuma é constituída de material orgânico (polifenólica, uréia-formaldeído ou de poliestireno), inerte, apresenta $\mathrm{pH}$ ácido, de manejo fácil e rápido, comercializada na forma de placas, com espessuras de 2 ou $4 \mathrm{~cm}$ e com as células pré-marcadas nas dimensões $2 \mathrm{~cm} \quad \mathrm{x} \quad 2 \mathrm{~cm}$ (BEZERRA NETO; BARRETO, 2012).

A espuma fenólica tem se mostrado um interessante e prático substrato para a produção de mudas para cultivo hidropônico, em virtude de poder ser transplantada conjuntamente com a muda para o local definitivo, protegendo assim o sistema radicular, além de que apresenta a vantagem de não deixar resíduos na solução nutritiva (SCHULZ, 2008).

Para utilizar a espuma fenólica faz-se necessário uma lavagem precedente das placas objetivando reduzir a acidez resultante do processo de fabricação. Caso contrário, esses resíduos prejudicarão a germinação, a emergência e o crescimento das plântulas (PAULUS et al., 2005).

Porém, recentemente já é possível encontrar a venda espumas fenólicas com $\mathrm{pH}$ próximo ao neutro, em torno de $6,0( \pm 0,5)$, para facilitar ao produtor desenvolver o trabalho, evitando o pré-tratamento e acompanhamento do $\mathrm{pH}$ até chegar ao nível ideal. No entanto, ainda não existem estudos comparativos entre essa nova tecnologia e as que vêm sendo empregadas até então.

O objetivo deste trabalho foi avaliar a produção de mudas de cultivares de alface utilizando duas espumas fenólicas em Altamira, Pará.

\section{MATERIAL E MÉTODOS}

O experimento foi conduzido em Altamira-PA, em uma horta hidropônica particular, com a seguinte localização geográfica: latitude sul $03^{\circ} 13^{\prime} 54^{\prime}$ ' e longitude oeste $52^{\circ} 13^{\prime}$ 55" com altitude de 104,0 metros do nível do mar.

O clima da região é classificado como tropical úmido, e de acordo com estudo realizado por Silva (2004), com dados da cidade de Altamira, PA, relativos ao período de 1990 a 2002, indicam que a precipitação média anual é de $2.123 \mathrm{~mm}$, caracterizada por período chuvoso entre os meses de dezembro a junho, com $74 \%$ das chuvas, sendo março o mês com maior precipitação pluvial, com média de 379,2 $\mathrm{mm}$.

Ainda segundo Silva (2004), a temperatura média diária é de $27,3{ }^{\circ} \mathrm{C}$, com média das máximas e das mínimas de $32,4{ }^{\circ} \mathrm{C}$ e $22,1^{\circ} \mathrm{C}$, respectivamente. A umidade relativa do ar média mensal de $80,4 \%$. No mês de julho acontece o período de maior insolação, com 7,4 horas de brilho solar médio diário.

O delineamento experimental constou em um esquema fatorial $2 \times 6$ (substratos e cultivares), perfazendo doze tratamentos com quatro repetições distribuídas inteiramente ao acaso, totalizando 48 unidades experimentais. Cada unidade experimental continha 25 células (cubos de $2 \mathrm{~cm} \times 2$ $\mathrm{cm} \times 2 \mathrm{~cm}$ ). Os dois substratos comerciais foram as espumas fenólicas Green $\mathrm{Up}{ }^{\circledR}$ com $\mathrm{pH} 6.0( \pm 0,5)$, ao qual não foi realizado pré-tratamento e Green $\mathrm{Up}{ }^{\circledR}$ com $\mathrm{pH} 2,6( \pm 0,5)$, que passou pelo processo de pré-tratamento para reduzir a acidez. 
As seis cultivares de alface utilizadas foram: Multiblond 3, Alcione, Caipira, Lucy Brown, Solaris e Amanda.

A semeadura foi realizada nas placas de espumas fenólicas acondicionadas em bandejas de poliestireno expandida com 300 células cada, onde se colocou uma semente peletizada por célula, em orifício de $3 \mathrm{~mm}$ de profundidade e $2 \mathrm{~mm}$ de diâmetro, feitos manualmente com um furador metálico adaptado para tal função.

As sementes foram adquiridas levando-se em consideração os dados de pureza e germinação, devido os mesmos ser os mais próximos possíveis para que o efeito dos substratos não sofresse influência dessas características.

Após o semeio, a espuma com pH baixo passou pelo processo de tratamento que consistiu em lavagem em água corrente por um minuto e aplicação de solução nutritiva até atingir o pH 5,5. Já a espuma de $\mathrm{pH}$ 6,0 passou apenas pelo processo de encharcamento até saturar com água. Posteriormente, todos os tratamentos foram acondicionados em uma câmara escura, confeccionada com madeira e lona preta, onde permaneceram durante 48 haras para estimular a germinação.

Depois desse processo, as bandejas foram colocadas na sementeira, uma bancada de madeira com 1,5 m de altura, onde permaneceu até as mudas encontrarem-se aptas ao transplantio para o berçário.

No decorrer deste experimento as plântulas foram irrigadas manualmente duas vezes ao dia com o auxílio de um irrigador, procurando manter as tensões de água no substrato sempre próximas a capacidade de vaso e a saturação máxima de modo a satisfazer as necessidades hídricas da cultura nesse estádio.

As avaliações de emergência foram iniciadas às 48 horas após a semeadura, sendo realizadas observações com 2; 3; 4 e 5 dias após a semeadura (DAS), sendo computadas somente as plântulas normais de acordo as com regras para análises de sementes (BRASIL, 2009).

Para determinar a porcentagem de germinação (PGE), as plântulas foram avaliadas até o quinto DAS, e esta variável foi calculada de acordo com Labouriau e Valadares (1976), sendo utilizada a fórmula: $\mathrm{G}=(\mathrm{N} / \mathrm{A})$. 100; onde: $\mathrm{G}=$ germinação; $\mathrm{N}$ = número total de sementes germinadas; $\mathrm{A}=$ número total de sementes colocadas para germinar.

Com relação ao índice de velocidade de emergência (IVE), foi utilizada a fórmula proposta por Maguirre (1962), onde foi determinado registrando-se diariamente, a partir do segundo DAS, o número de sementes germinadas até o $15^{\circ}$ DAS.

Foi considerada como emergidas as plântulas que apresentaram os cotilédones totalmente livres e normais. $\mathrm{O}$ IVE foi calculado de acordo com a equação: IVE $=\mathrm{E} 1 / \mathrm{N} 1+$ $\mathrm{E} 2 / \mathrm{N} 2+\ldots+\mathrm{En} / \mathrm{Nn}$, em que E1, E2 e En - número de plântulas normais computadas na primeira, segunda e última contagem e N1, N2 e Nn - número de dias após a implantação do teste.

Também foram feitas avaliações ao fim do experimento, 15 dias após a emergência, quando completada a fase de mudas, onde analisou-se as seguintes características: Altura da planta (ALT) - Medida do substrato ao ápice da folha mais nova em $(\mathrm{cm})$, utilizando um escalímetro; Número de folhas (NUF) - Contagem direta das folhas.

Os dados foram submetidos a análise de variância com o auxílio do programa estatístico ASSISTAT, Versão 7.7 beta (2014). As médias dos tratamentos foram comparadas aplicando-se o Teste de Tukey ao nível de 5\% de probabilidade.

\section{RESULTADOS e DISCUSSÃO}

Ao analisar a Tabela 1, verifica-se que houve diferença significativa a $1 \%$ de probabilidade para altura da planta em função dos substratos testados, assim como diferença significativa a $5 \%$ de probabilidade para o índice de velocidade de emergência (IVE).

Para porcentagem de germinação e número de folhas não houve diferença estatística. Em relação às cultivares, houve diferença significativa para todas as características avaliadas. Já a interação entre substratos e cultivares apresentou diferença significativa a $5 \%$ de probabilidade para o IVE e altura da planta.

Tabela 1. Resumo da análise de variância (teste F) da porcentagem de germinação (PGE), do índice de velocidade de emergência (IVE), número médio de folhas (NUF) e altura média da planta (ALT). Altamira (PA). UFPA, 2014.

\begin{tabular}{|c|c|c|c|c|c|}
\hline Fonte de Variação & GL & PGE & IVE & NUF & ALT \\
\hline Substrato (S) & 1 & $0,7680 \mathrm{~ns}$ & $4,2668 *$ & $1,4752 \mathrm{~ns}$ & $48,6663 * *$ \\
\hline Cultivar (C) & 5 & $46,6464 * *$ & $117,8392 * *$ & $77,6126 * *$ & $88,6289 * *$ \\
\hline $\mathrm{SxC}$ & 5 & $0,8256 \mathrm{~ns}$ & $2,9047 *$ & $1,0256 \mathrm{~ns}$ & $2,9089 *$ \\
\hline Tratamentos & 11 & $21,6480 * *$ & $55,2715 * *$ & $35.8787 * *$ & $46,0323 * *$ \\
\hline Resíduo & 36 & & & & \\
\hline $\mathrm{CV}(\%)$ & & 5,91 & 4,73 & 1,32 & 8,94 \\
\hline
\end{tabular}

Ao avaliar o pré-tratamento da espuma fenólica na produção de mudas de alface, cultivar Verdinha de Vitória, Bezerra Neto et al. (2010) identificaram nas parcelas sem tratamento taxa de germinação das sementes de $23,04 \%$, valor este estatisticamente $(\mathrm{P}<0,05)$ inferior aos demais tratamentos, os quais não diferiram entre si e apresentaram médias variando de 68 a 81,28\% de germinação. Além disso, as plântulas morreram após a germinação. 
Assim, a baixa germinação associada à morte das plântulas certamente está relacionada à elevada acidez da espuma fenólica, que apresenta $\mathrm{pH}$ baixo 2,6 $( \pm 0,5)$ na condição que é comercializada. Portanto, se faz necessário realizar o pré-tratamento das espumas fenólicas ácidas para propiciar elevação do $\mathrm{pH}$ do substrato e, consequentemente, promover melhor índice de germinação e desenvolvimento das mudas.

Nesse sentido, os resultados obtidos neste trabalho demonstraram que ao utilizar espuma fenólica com $\mathrm{pH}$ neutro, obteve-se resultados compatíveis com aquela que passou por um pré-tratamento antes da semeadura.

A porcentagem de germinação mais elevada foi obtida com a espuma fenólica de $\mathrm{pH}$ 6,0, conforme apresentado na Figura 1. Para este caráter não houve diferença significativa entre as espumas com uma média de $89,1 \%$. Já entre as cultivares, a cultivar Caipira foi a que teve o menor desempenho com apenas $63,5 \%$ de germinação contra uma média de $94,3 \%$ das outras cinco cultivares.

Figura 01. Porcentagem geral de germinação das cultivares e porcentagem de germinação em cada tipo de substrato. Altamira (PA). UFPA, 2014

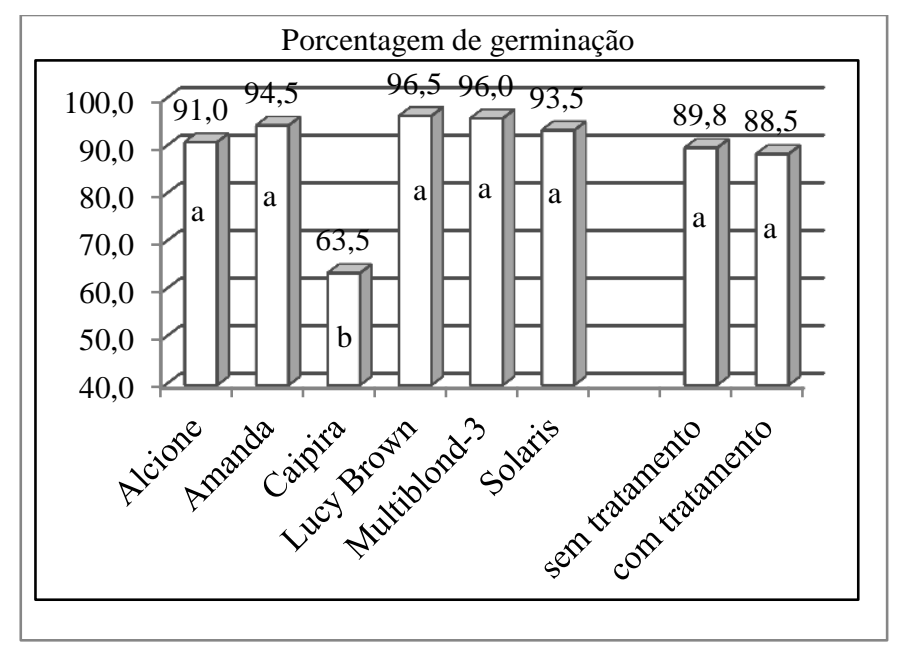

Substratos comerciais como as espumas fenólicas têm como característica uma porcentagem de micro poros considerada adequada para a produção de mudas de hortaliças, o que confere a esse substrato uma capacidade de retenção de água satisfatória, influenciando positivamente a germinação e o desenvolvimento do sistema radicular das mudas (GUERRINI; TRIGUEIRO, 2004).

Com exceção da cultivar Caipira, as demais cultivares tiveram resultados próximos aos fornecidos pelos produtores das semente, que indicavam em seus rótulos valores variando de 95 a $99 \%$ de germinação dependendo de cada cultivar.

Para o índice de velocidade de emergência (IVE) o melhor resultado entre os substratos foi obtido com a espuma fenólica que passou pelo tratamento. Já entre as cultivares tiveram melhores desempenhos foram a Lucy Brown e multiblond-3 e pior desempenho a cultivar Caipira (Figura 02).

Figura 02. IVE das cultivares e em cada tipo de substrato. Altamira (PA). UFPA, 2014.

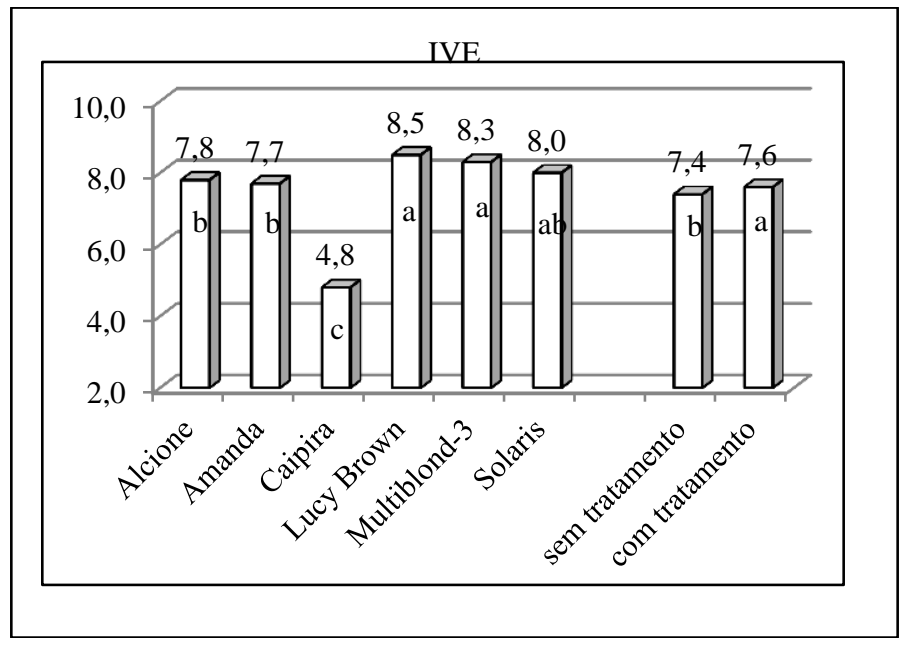


Vieira \& Krzyzanowsky (1999) afirmam que para a variável IVE quanto maior o valor apresentado, maior é a capacidade das sementes expressarem seu potencial. Pode-se inferir que provavelmente as sementes de alface apresentaram maiores habilidades para germinar na espuma que passou pelo tratamento, apesar de que a diferença foi significativa apenas a $1 \%$.

Quanto mais rápido ocorrer a germinação das sementes e a imediata emergência das plântulas, menos tempo as mesmas ficarão sob condições adversas, passando pelos estádios iniciais de desenvolvimento de forma mais acelerada (MARTINS; NAKAGAWA; BOVI, 1999). Essas condições adversas podem ser redução da umidade próxima à semente, que é essencial à germinação ou mesmo a ação de microrganismos, que causem alguma deterioração à semente ou à plântula.
Ao avaliar os efeitos de diferentes combinações de substratos na geminação e desenvolvimento de mudas de diferentes cultivares de alface, Silva et al. (2008) consideraram que o substrato composto por areia + Plantmax ${ }^{\circledR}$ foi o que promoveu a maior rapidez de emergência de plântulas, e as cultivares Babá de Verão e Crespa sem cabeça apresentaram os maiores índices de velocidade de emergência, diferindo estatisticamente da variedade Americana Júlia, onde o IVE foi inferior.

Aos 15 DAS o número de folhas por planta não apresentou diferenças significativas $(\mathrm{P}>0,05)$ entre os tipos de espumas fenólicas com uma média de 3,4 folha/planta. Já entre as cultivares a cv. Alcione obteve o menor desempenho com 3,1 folha/planta (Figura 03).

Figura 03. Número de folhas por planta das cultivares e número de folhas em cada tipo de substrato. Altamira (PA). UFPA, 2014

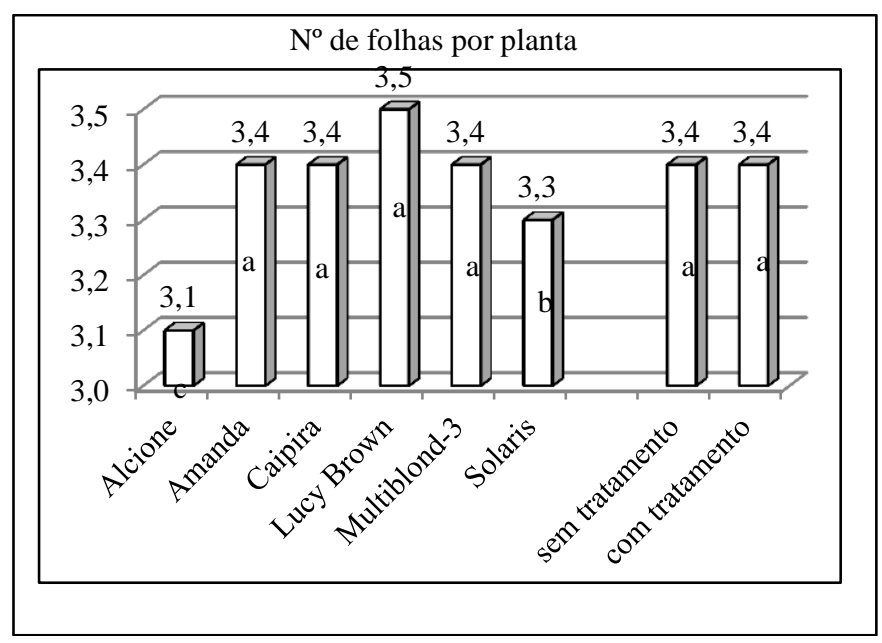

A média foi superior ao encontrado por Monteiro (2012), onde ao avaliar o efeito de diferentes substratos na produção de mudas de alface, encontrou o melhor valor de 3,2 folha/planta para o substrato $75 \%$ composto orgânico $+25 \%$ substrato comercial Plantmax ${ }^{\circledR}$ e o menor valor de 2,6 para o substrato $100 \%$ solo (Latossolo Vermelho), neste trabalho a avaliação também ocorreu aos quinze dias após o semeio.

Ao avaliar o desenvolvimento de mudas de alface da cv. Vitória de Santo Antão em substratos alternativos, Cabral et al.(2011) identificaram que o substrato com $50 \%$ de esterco bovino e $50 \%$ de palhada de feijão, ao ser comparado ao produto comercial Plantmax, destacou-se positivamente na maioria das variáveis consideradas, atingindo médias semelhantes aos demais tratamentos para a porcentagem de germinação e estabilidade de agregados, e médias superiores para todas as demais variáveis, incluindo neste caso o número de folhas por planta.

$\mathrm{Na}$ avaliação do desempenho de mudas de alface da cultivar Verônica nos substratos alternativos, Bioplant ${ }^{\circledR}$, Terra preta + húmus, Terra preta + húmus + fibra de coco, Terra preta + Torta de filtro + húmus, observaram que para a variável número de folhas não houve diferença significativa pelo teste de Tukey a $5 \%$ de probabilidade. Portanto, a quantidade de folhas produzidas nos substratos alternativos foi semelhante à proporcionada pelo substrato comercial, com uma produção média de cinco folhas por muda, aos 28 DAS (COSTA et al., 2012).

Uma muda ideal de alface, de acordo com Camargo, (1992), deve apresentar de 4 a 6 folhas definitivas. Essa variável é bastante importante devido à informação de que o substrato proporcionará um aparato fotossintético eficiente, para que a planta possa sobreviver após o transplante.

Percebe-se que todas as cultivares utilizadas neste trabalho tiveram um bom desenvolvimento relacionado ao número de folhas, obtendo valores próximos, com exceção da cultivar Alcione, que obteve o menor resultado, fazendo com que na comparação das médias houvesse diferença significativa entre as cultivares.

Para a característica altura da planta, a espuma fenólica que não passou por tratamento proporcionou $\mathrm{o}$ melhor desempenho, e o resultado foi estatisticamente significativo a nível de $1 \%$ de probabilidade. Em relação às cultivares, a cv. Lucy Brown alcançou o melhor resultado, e este bem acima da média das demais e as cultivares Alcione e Caipira tiveram os piores valores, bem abaixo da média, o que fez com que ao compara-las, houvesse uma diferença significativa (Figura 04). 
Figura 04. Altura das plantas entre cultivares e entre os tipos de substratos. Altamira (PA). UFPA, 2014

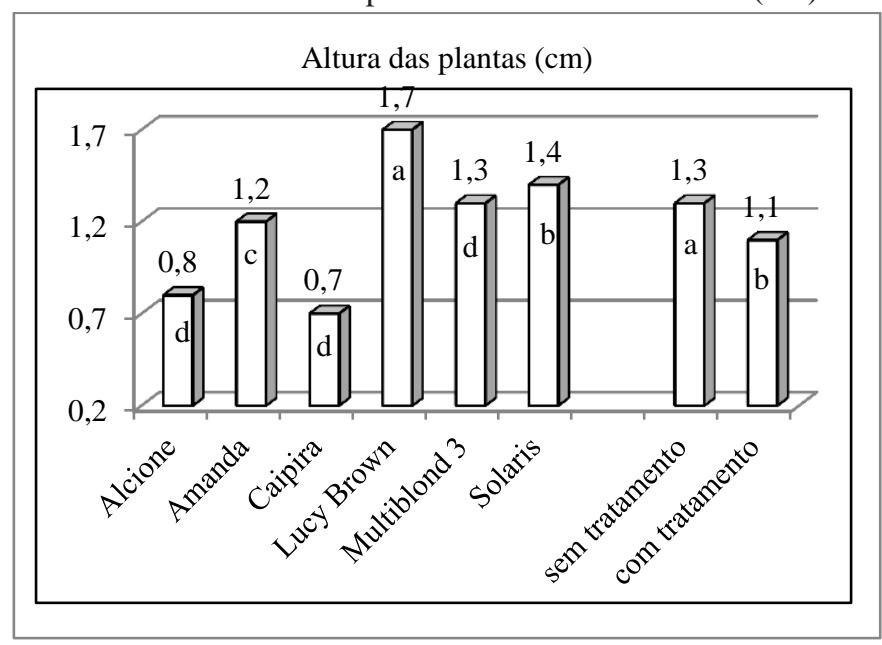

Análise de crescimento realizada por Lopes et al. (2007) em mudas de alface cultivar Verônica semeadas nos substratos comerciais Golden Mix ${ }^{\circledR}$, Plantmax ${ }^{\circledR}$ e Plug Mix ${ }^{\circledR}$ identificou altura de planta com $2,85 \mathrm{~cm} ; 3,10 \mathrm{~cm} \mathrm{e}$ $3,33 \mathrm{~cm}$, respectivamente. Esses valores de altura bem acima dos encontrados nesta pesquisa pode ser explicado devido as espumas fenólicas ser um substrato inerte, e, portanto, não interfere na absorção de nutrientes pelas plantas.

No entanto, os autores citados utilizaram fertirrigação e também foram colocadas sob sombrite.

\section{CONCLUSÕES}

A espuma fenólica sem tratamento foi a que obteve os melhores resultados para os itens analisados, com exceção do IVE, demonstrando que ela pode ser utilizada sem nenhum pré-tratamento, o que facilita e diminui a mão de obra.

Para todas as variáveis analisadas, a cultivar Lucy Brown apresentou os melhores resultados em contraposição a cv. Caipira que foi a portadora dos piores resultados de todos os caracteres avaliados, com exceção do número de folhas.

\section{REFERÊNCIAS BIBLIOGRÁFICAS}

BEZERRA NETO, E.; SANTOS, R.L.; PESSOA, P.M.A.; ANDRADE, P.K.B.; OLIVEIRA, S.K.G.; MENDONÇA, I.F. Tratamento de espuma fenólica para produção de mudas de alface. Revista Brasileira de Ciências Agrárias 5: 418-422. 2010. (Online).

BEZERRA NETO, E., BARRETO, L.P. Técnicas de hidroponia. Anais da Academia Pernambucana de Ciência Agronômica, Recife, vols. 8 e 9, p.107-137, 2012.

BRASIL. Ministério da Agricultura, Pecuária e Abastecimento. Teste de germinação. In:Regras para análise de sementes - Brasília : Mapa/ACS, 2009. cap.5, p.147-224. ISBN 978-85-99851-70-8.

CABRAL, M.B.G.; SANTOS, G. de A.; SANCHEZ, S.B.; LIMA, W.L. de; RODRIGUES, W.N. Avaliação de substratos alternativos para produção de mudas de alface utilizados no sul do estado do espírito santo. Revista Verde (Mossoró - RN - Brasil) v.5, n.1, p. 43 - 48. 2011.
CAMARGO, L.S. As hortaliças e seu cultivo, 3 ed., rev. e atual. Campinas: Fundação Cargill, 252p. 1992.

CAVARIANNI, R.L; CONRADI, M.M; CECÍLIO FILHO, A.B; MAY, A; CAZETTA, J.O. 2004. Acúmulo de nitrato em cultivares de rúcula em função da concentração de nitrogênio na solução nutritiva. In: CONGRESSO BRASILEIRO DE HORTICULTURA, 44. Resumos. Campo Grande, SOB (CD-ROM).

COSTA, K.D. da S.; CARVALHO, I.D.E. de; FERREIRA, P.V.; DA SILVA, J.; TEIXEIRA, J. dos S. Avaliação de substratos alternativos para a produção de mudas de alface. Revista Verde (Mossoró - RN), v. 7, n. 5, p. 5862, dezembro de 2012 (Edição Especial).

FURLANI, P.R.; SILVEIRA, L.C.P.; BOLONHEZI, D.; FAQUIN, V. Cultivo Hidropônico de Plantas: Parte 3 Produção de mudas para hidroponia. 2009. Artigo em Hypertexto. Disponível em: <http://www.infobibos. com/Artigos /2009_2/hidroponiap3/index.htm>. Acesso em: 28/10/2014.

GUERRINI, I.A.; TRIGUEIRO, R.M. Atributos físicos e químicos de substratos compostos por biossólidos e casca de arroz carbonizada. Revista Brasileira de Ciência do Solo, v. 28, n. 6, p. 1069-1076, Viçosa, 2004.

HENZ, G.P.; SUINAGA, F.A. Tipos de alface cultivados no Brasil. Brasília, DF: Embrapa Hortaliças, 2009. 7p. (Embrapa Hortaliças. Comunicado Técnico, 75).

KÄMPF, A.N. Análise física de substratos para plantas. In: Boletim Informativo, Sociedade Brasileira de Ciência do Solo, v.26, n.1, p.5-7, 2001.

LABORIAL, L.G.; VALADARES, M.B. On the germination of seeds of Calotropis procera. Anais da Academia Brasileira de Ciências, n.48, 174-186. São Paulo, 1976.

LOPES, J. L.W.; BOARO, C.S.F.; PERES, M.R.; GUIMARÃES, V.F. Crescimento de mudas de alface em diferentes substratos. Biotemas, 20 (4): 19-25, ISSN $0103-1643.2007$. 
LUZ, J.M.Q.; GUIMARÃES, S.T.M.R.; KORNDÖRFER, G.H. Produção hidropônica de alface em solução nutritiva com e sem silício. Horticultura Brasileira, v.24, p.295-300, 2006.

MACIEL, M.P.R. Produção de girassol ornamental com uso de águas salobras em sistema hidropônico NFT. Bras. Eng. Agricola Ambiental, v.16, n.2, p.165-172, 2012.

MAGUIRE, J.D. Speed of germination aid in selection and evaluation for seedling emergence and vigor. Crop Science, Madison, v. 2, n. 2, p. 176-177, 1962.

MARTINS, C.C.; NAKAGAWA, J.; BOVI, M.L.A. Efeito da posição da semente no substrato e no crescimento inicial das plântulas de palmito-vermelho (Euterpe espiritosantensis Fernades - Palmae). Revista Brasileira de Sementes, 21(1):164-173. Brasília, 1999.

MEDEIROS, C.A.B.; STRASSBURGER, A.S.; ANTUNES, L.E.C. Avaliação de substratos constituídos de casca de arroz no cultivo sem solo do morangueiro. Horticultura Brasileira, v. 26, n. 2, p. 4827-4831, 2008.

MELO, D.M.; CASTOLDI, R.; CHARLO, H. C. O.; GALATTI, F. de S.; BRAZ, L. T. Produção e qualidade de melão rendilhado sob diferentes substratos em cultivo protegido. Revista Caatinga, v. 25, n. 1, p. 58-66, 2012.

MONTEIRO, G.C.; CARON, B.O.; BASSO, C.J.; ELOY, E.; ELLI, E.F. Avaliação de substratos alternativos para produção de mudas de alface.Enciclopédia Biosfera, Centro Científico Conhecer v.8, N.14; p. 1 40-148. Goiânia, 2012.

PAULA, L.; ROLIM, M. M.; NETO, E. B.; SOARES, T. M.; PEDROSA, E. M. R.; SILVA, Ê. F. de F. e. Crescimento e nutrição mineral de milho forrageiro em cultivo hidropônico com soro de leite bovino. Revista Brasileira de Engenharia Agrícola e Ambiental, v. 15, n. 9, p. 931-939, 2011.

PAULUS, D; MEDEIROSS, L.P; SANTOS, O.S.; RIFFEL, C; FABBRIN, E; PAULUS, E. Substratos na produção hidropônica de mudas de hortelã. Horticultura Brasileira, v.23, p.48-50, 2005.

QUEIROZ, I S.R. LEITÃO, A. R. F.; FERREIRA, L. L.; DIAS, N. da S.; COSME, C. R.; MOTA, A. F. Tolerância da berinjela à salinidade cultivada em substrato de fibra de coco. Revista Agropecuária Científica no Semiárido, v. 9, n. 2, p. 15-20, 2013.

SANTOS JÚNIOR, J.A.; GHEYI, H.R.; GUEDES FILHO, D.H.; DIAS, N. da S.; SOARES, F.A.L. Cultivo de girassol em sistema hidropônico sob diferentes níveis de salinidade. Revista Ciência Agronômica, v.42, p.842$849,2011$.

SCHULZ, J. Alternativas de substratos utilizados na hidroponia. 2008. Disponível em: <http://www.portalhidroponia.com.br/index.php?option $=$ com_content

\&task=view\&id=152\&itemid=1 >acesso em 20/10/2014.

SETUBAL, J.W.; NETO, A.F.C. Efeitos de substratos alternativos e tipos de bandejas na produção de mudas de pimentão. Horticultura Brasileira (Suplemento), v. 18, p. 593-594, jul. 2000.

SILVA, C. da S. e; Caracterização Agrometeorológica do Município de Altamira/PA. Altamira: UFPA. Trabalho de Conclusão de Curso (Monografia de graduação),Licenciatura Plena em Ciências Agrárias Universidade Federal do Pará - CampusUniversitário de Altamira, 2004. 40 p.

SILVA, E.A. da; MENDONÇA, V.; TOSTA, M. da S.; OLIVEIRA, A.C. de; REIS, L.L. dos; BARDIVIESSO, D.M. Germinação da semente e produção de mudas de cultivares de alface em diferentes substratos. Semina: Ciências Agrárias, v.29, n. 2, p. 245-254. Londrina, abr./jun. 2008.

TRANI, P.E.; NOVO, M.C.S.S; CAVALLARIO JÚNIOR, M.L; TELES, L.M.G. Produção de mudas de alface em bandejas e substratos comerciais. Horticultura Brasileira, v.22, n.2, p.290-294, 2004.

TRAVASSOS, K.D.; SOARES, F.A.L.; GHEYI, H.R.; SILVA, D.R.S.; NASCIMENTO, A.K.S.; DIAS, N. da S. Produção de aquênio do girassol irrigado com água salobra. Revista Brasileira de Engenharia Agrícola e Ambiental, v.15, p.371-376, 2011.

VIEIRA, R.D.; KRZYZANOWSKI, F.C. Teste de condutividade elétrica. In: KRZYZANOWSKI, F.C.; VIEIRA, R.D.; FRANÇA NETO, J.B. (Ed.). Vigor de sementes: conceitos e testes.Brasília: ABRATES, 1999. Cap. 4, p. 1-26. 